\title{
Combating Airway Issues with Elective Use of an I Gel in a Child with Goldenhar Syndrome
}

\author{
Shilpi Sethi ${ }^{1}$, Manish Sethi ${ }^{2}$
}

\section{Abstract}

Introduction: Goldenhar syndrome is an oculoauriculovertebral spectrum attributed to the developmental anomalies of the first and second brachial arches. Its typical presentation in children with hemifacial microsomia poses a dual challenge for the anaesthesiologist on account of difficult airway often compounded with systemic abnormalities.

Case Report: We describe a case report wherein a 5-year-old female presented to the oculoplastic clinic of our hospital for surgical removal of limbal dermoid under general anaesthesia. Airway examination revealed classical facial asymmetry with underdevelopment of jaw bone coupled with protruding incisors. A predicted difficult airway, more so in a child led us to choose an anaesthesia technique with preservation of spontaneous breathing and planned use of supraglottic device in the form of an I Gel for airway management.

Conclusion: The aim of this case report is to highlight the anaesthetic implications of this not so uncommon entity presenting to ophthalmology and ENT clinics. A thorough preoperative assessment, adequate preparedness and alternative plans are keys for successful airway management in such syndromic children.

Keywords: Goldenhar syndrome, Hemifacial microsomia, I Gel

\section{Introduction}

Goldenhar (GH) syndrome also known as oculoauriculovertebral dysplasia was first described by an ophthalmologist Mauree Goldenhar in 1952 [1]. It affects one in every 3000 to 5000 births and its characteristic abnormality is faulty development of eye, ear and spine. This leads to classic facial features known as hemifacial microsomia by virtue of which one side of face is underdeveloped. Frequently, systemic involvement of body organs like heart, kidney, lungs, nervous system and spine may coexist. It is not uncommon for these children to present for the correction of craniofacial anomaly like removal of ocular dermoid cyst, cosmetic correction of external ear deformities, cochlear implants for hearing loss, spinal deformity correction and cardiac surgeries. It poses significant challenges for the attending anaesthesiologist owing to the difficult airway along with coexisting systemic abnormalities.

\section{Case Report}

A 5-year-old female weighing $15 \mathrm{~kg}$ presented to oculoplasty speciality clinic of our ophthalmology out patient services with painless swelling in the right eye since birth. On ocular examination, her visual acuity was 20/400 in right eye with hyperopic astigmatism and left eye was normal. Her right eye showed an elevated sessile mass at inferotemporal limbus with keratinisation and cilia on surface clinically pointing to diagnosis of limbal dermoid requiring surgical excision (Fig. 1). Ear examination revealed preauricular tags and pits
(Fig. 2 ). Facial asymmetry was obvious with underdevelopment of right maxilla (Fig. 3). Airway evaluation exhibited a Mallampati Class II with large tongue, protruding incisors and micrognathia. Neck movements were normal. Wilson score was 2 ( weight $=0$, head neck movements $=0$, jaw movement $=0$, jaw structure $=1$, teeth structure $=1$ ). Central nervous system and spine examination was normal. A thorough cardiac evaluation was carried out to rule out any associated congenital heart defects. There was no history of snoring or stridor. Chest and cervical spine X-ray was normal. Other investigations were unremarkable. A written informed parental consent was taken, explaining all the risks involved in the management of a difficult airway. A difficult airway cart was set up with age and weight appropriate endotracheal tubes, supraglottic devices, oral and nasal airways, curved and straight blades, bougie, stylet and Ambu Kings vision videolaryngoscope. We do not have a fibreoptic bronchoscope (FOB) at our hospital. Consent for surgical tracheostomy was taken and an ENT surgeon was available as stand by. Intravenous cannulation was done after application of EMLA cream. Premedication with injection atropine $0.02 \mathrm{mg} / \mathrm{kg}$ and injection paracetamol $225 \mathrm{mg}$ was given over 15 minutes. Standard monitoring included NIBP, ECG, SpO2 and ETCO2. Preoxygenation with the $100 \%$ oxygen was done targeting FEO2 value $>0.9$. Patient was induced with injection propofol $2.5 \mathrm{mg} / \mathrm{kg}$ and injection ketamine $0.25 \mathrm{mg} / \mathrm{kg}$ with $3-4 \%$ sevoflurane in oxygen. The child could be adequately mask ventilated. I Gel size 2 (Intersurgical Ltd. Berkshire,

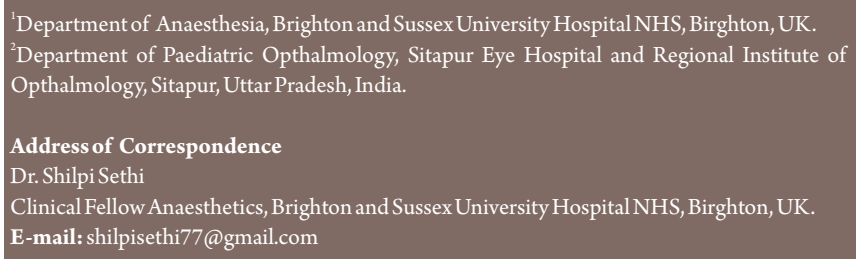

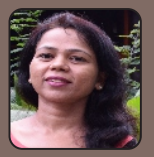

Dr. Shilpi Sethi

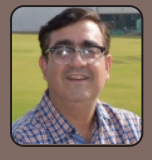

Dr. Manish Sethi

Submitted: 23/5/2021; Reviewed: 18/6/2021; Accepted: 8/8/2021; Published: 10/9/2021

DOI: 10.13107/jaccr.2021.v07i03.188

This is an Open Access journal, and articles are distributed under the terms of the Creative Commons Attribution Non-Commercial-Share Alike 4.0 License (http://creativecommons.org/licenses/by-nc-sa/4.0) which allows others to remix, tweak, and build upon the work non-commercially as long as appropriate credit is given and the new creation are licensed under the identical terms. 

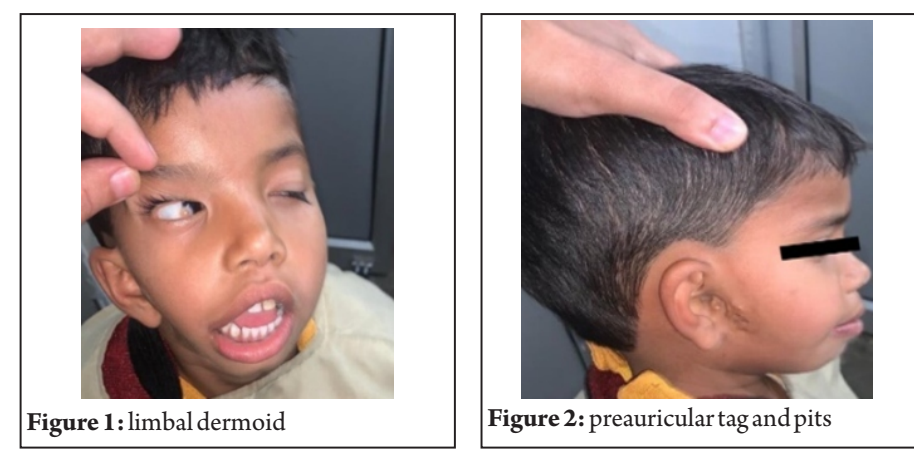

UK) was placed in a single attempt when the jaw was relaxed (Fig. 4). Manual inline stabilisation maintained from the time of induction to successful placement of I Gel. Once adequate ventilation was ensured by means of bilateral auscultation, chest movements, $\mathrm{SpO} 2$ and square wave capnography, injection atracurium $0.3 \mathrm{mg} / \mathrm{kg}$ was given for maintenance along with $1: 1 \mathrm{O} 2$ and $\mathrm{N} 2 \mathrm{O}$ with $1.5 \%$ sevoflurane. A single medial canthal peribulbar block with $3 \mathrm{ml}$ of $0.5 \%$ bupivacaine was given for supplemental analgesia. Surgery lasted for 50 minutes. At the end of surgery, I Gel was removed after reversal of neuromuscular block. There was no episode of any desaturation and hemodynamics were maintained within normal limits. Post operative period was uneventful.

\section{Discussion}

In patients of $\mathrm{GH}$ syndrome, presence of craniofacial and vertebral anomalies make airway management very challenging [2]. Literature is replete with numerous methods of successful airway handling in $\mathrm{GH}$ syndrome. There is a case report of uneventful general anaesthesia utilizing laryngeal mask airway (LMA) in 10-year-old GH patient with severe microstomia for ophthalmic surgery [3]. Initial failed attempt of difficult laryngoscopy with curved blade and 4.5 number ET tube was averted by using straight blade and 4.0 ET tube in a 4.5 years old child with GH [4]. After two sequential failed attempts with direct larygoscopy and later videolaryngoscopy, successful tracheal intubation using fibreoptic bronchoscope via an I Gel was used in a 4year-old child with $\mathrm{GH}[5]$. Successful intubation utilizing glidescope, [6] and Airtrach [7] has been reported in children with GH.

Lack of FOB at our centre coupled with different degrees of glottic exposure owing to different angulation of videolaryngoscope blades in a predicted difficult airway led us to choose I Gel as our first choice. Supraglottic airway (SGA) devices has established its safety in children and I Gel is a novel innovation amongst these. It is used in a planned way as a primary device to secure airway in known difficult airway [8]. I Gel was specially chosen because it is second generation SGA with gastric drainage tube and various studies of simulated difficult airway by using cervical collar has shown insertion success
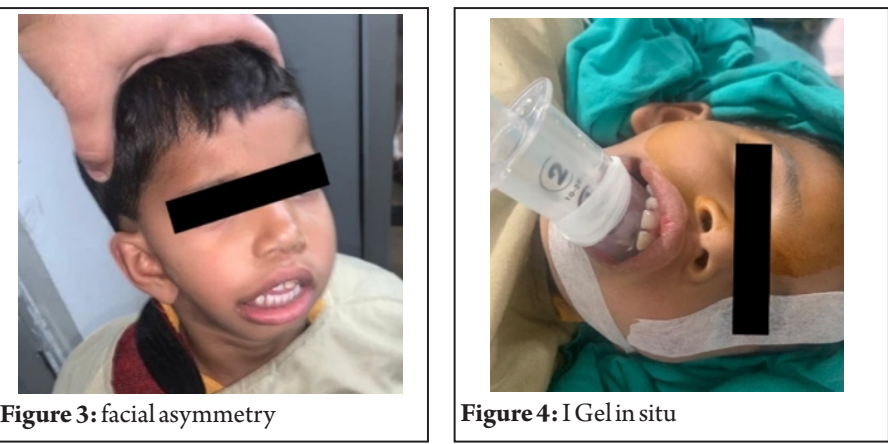

with less downfolding of epiglottis [9]. Moreover, I Gel can be used as a conduit for tracheal tube placement. Manual inline stabilisation was done because normal imaging studies in cases of GH does not completely obviate the chances of atlantooccipital subluxation due to cervical muscles and jaw relaxation under anaesthesia [10]. In all anticipated difficult airway, it is better to keep the patient breathing spontaneously till airway is secured. It is also a good idea to maintain oxygenation during airway instrumentation via nasal prongs. We avoided long acting muscle relaxant until successful placement of I Gel. Our alternate plan in case I Gel wouldn't maintain adequate ventilation, and mask ventilation being adequate was to give a trial of short acting muscle relaxant like succinylcholine and perform videolaryngoscopy. In the absence of videolaryngoscopy a check laryngoscopy to assess ability to visualize glottis can be done. Had $\mathrm{SpO} 2$ been falling with mask ventilation, we would have woken up the patient.

\section{Conclusions}

FOB remains a gold standard in anticipated difficult paediatric airway but availability and skills are concerning issues. Airway management has to be tailored according to the setup and skills. Elective use of I Gel in challenging syndromic children like $\mathrm{GH}$ is a reasonable choice.

\section{Clinical Message}

Difficult airway keeps one at an edge and preplanning, repeat planning and alternate planning is certainly the key to avoid any catastrophe.

Declaration of patient consent: The authors certify that they have obtained all appropriate patient consent forms. In the form, the patient has given his consent for his images and other clinical information to be reported in the Journal. The patient understands that his name and initials will not be published, and due efforts will be made to conceal his identity, but anonymity cannot be guaranteed.

\section{Conflict of interest: Nil Source of support: None}




\section{References}

1. GoldenharM. Association of the eye and forcille In particular the epidermal dermoid syndrome - appendages Auricularies - fistula auris congenital and its relations with Mandibulo - facial dysostosis J Genat Hum 1952;1:243-86.

2. Madan R, Trikha A, Venkataraman RK, Batra R, Kalia P. Goldenhar's syndrome: an analysis of anaesthetic management. A retrospective study of seventeen cases [published correction appears in Anaesthesia 1990 May;45(5):424]. Anaesthesia. 1990;45(1):49-52. doi:10.1111/j.1365-2044.1990.tb14505.

3. Sukhupragarn W, Rosenblatt WH. Airway management in a patient with Goldenhar syndrome: a case report. J Clin Anesth. 2008;20(3):214-217. doi:10.1016/j.jclinane.2007.09.020.

4. Altintas F, Cakmakkaya OS. General anesthesia for a child with Goldenhar syndrome. Paediatr Anaesth. 2005;15(6):529-530. doi:10.1111/j.1460-9592.2005.01621.

5. Kim YL, Seo DM, Shim KS, et al. Successful tracheal intubation using fiberoptic bronchoscope via an I-gel ${ }^{\text {Twx }}$ supraglottic airway in a pediatric patient with Goldenhar syndrome -A case report-. Korean J Anesthesiol.2013;65(1):61-65. doi:10.4097/kjae.2013.65.1.61.
6. Milne AD, Dower AM, Hackmann T. Airway management using the pediatric GlideScope in a child with Goldenhar syndrome and atypical plasma cholinesterase. Paediatr Anaesth. 2007;17(5):484-487. doi:10.1111/j.1460-9592.2006.02149.

7. Khalil S, Vinh B. Successful intubation of a child with Goldenhar syndrome, who previously failed intubation, using an Airtraq. Paediatr Anaesth. 2010;20(2):204-205. doi:10.1111/j.14609592.2009.03223.

8. Jagannathan N, Sequera-Ramos L, Sohn L, Wallis B, Shertzer A, Schaldenbrand K. Elective use of supraglottic airway devices for primary airway management in children with difficult airways. Br J Anaesth. 2014;112(4):742-748. doi:10.1093/bja/aet411.

9. Theiler LG, Kleine-Brueggeney M, Kaiser D, et al. Crossover comparison of the laryngeal mask supreme and the i-gel in simulated difficult airway scenario in anesthetized patients. Anesthesiology. 2009;111(1):55-62. doi:10.1097/ALN.0b013e3181a4c6b9.

10. Choudhury M, Kapoor PM. Goldenhar syndrome: Cardiac anesthesiologist's perspective. Ann Card Anaesth. 2017;20(Supplement):S61-S66. doi:10.4103/0971-9784.197802.

\section{How to Cite this Article}

Sethi S, Sethi M | Combating Airway Issues with Elective Use of an I Gel in a Child with Goldenhar Syndrome | Journal of Anaesthesia and Critical Care Case Reports | September-December 2021; 7(3): 23-25. 